\title{
1. Introduction: towards the contextualization of knowledge management as a research field Anders Örtenblad
}

This book deals with rationally calculated translation (Røvik 1998; see also Røvik 2011) of knowledge management, with an ambition to make the idea of knowledge management better fit organizations in various specific contexts. This stands in contrast to the 'automatic' translation that takes place as knowledge management and other management ideas travel in time and space, which has been taken up elsewhere (for example, Czarniawska and Sevón 1996, 2005). For instance, there are works which show that how knowledge management is practised depends on organizational characteristics and national culture (Magnier-Watanabe and Senoo 2010; see also Ang and Massingham 2007; Chen et al. 2010). Rather than how knowledge management is actually practised in organizations in various contexts (which might differ between contexts), this book discusses whether or not and to what extent organizations in various contexts could and should practise knowledge management and how a given general model of knowledge management might have to be adapted to fully make sense in these various contexts.

Thus, one basic assumption here is that researchers better than others in an unbiased way are capable of advising on the relevance of a particular definition of knowledge management to organizations in various particular contexts. Another basic assumption in this book is that the idea of knowledge management is assumed to be used in practice, in contrast to being used symbolically and thereby mainly increase the legitimacy of the user, who does not even need to put the idea into practice (Meyer and Rowan 1977).

\section{THE RISE OF KNOWLEDGE MANAGEMENT AS A FASHIONABLE MANAGEMENT IDEA}

The term 'knowledge management' has been here for quite some time now; it occurred in academic works on learning and development in relation to organization and management, in the areas of public administration and 


\section{Handbook of research on knowledge management}

information management, as far back as the 1970s (Örtenblad 2007). But, actually, Caldwell (1967) had already in 1967 written about 'the management of knowledge' and 'knowledge managers'. These 'knowledge administrators' were supposed to see to that 'all relevant knowledge is brought to bear upon the problems that society needs to solve' (Caldwell 1967, p. 130).

In the introduction to a symposium on knowledge management in the Public Administration Review in 1975, the symposium editors described the theme of the symposium as the following: 'can man increase his [sic] understanding of how to develop, regulate, and use knowledge more effectively for the achievement of public values and objectives?' (Carroll and Henry 1975, p.567). In the same symposium, Gates (1975, p. 589) described knowledge management as 'the ability to manage or control not only the generation and dissemination of objective information but also the essentially subjective processes which mediate in the creation of meaning'. Even earlier, Henry (1974, p. 994) had defined knowledge management as 'public policy for the production, dissemination, accessibility, and use of information'.

Beal used the term in a paper about knowledge dissemination to developing countries, and defined it as where knowledge is 'monitored, screened, indexed, catalogued, packaged and stored in a form which is readily retrievable at access points for functional search, use and dissemination' (Beal 1980, p. 6). There were also those who wrote about 'the management of knowledge' in business journals, but without using the specific label of knowledge management. For instance, Van Mesdag (1983, p. 39) reasoned that 'companies manage other assets - why not knowledge?' All the old literature in which the term knowledge management was used, though, is rarely cited in today's literature on knowledge management.

The management of knowledge did perhaps not become an 'idea' in its own right, or an idea that all organizations are said to be in need to adopt (and thus a panacea), until the late 1980s and early 1990s. Such an idea can develop much thanks to the fact that there is a 'guru' and a 'bible' (that is, best-seller). Ikujiro Nonaka seems to have been somewhat of a guru, but he actually never used the specific label of knowledge management, or even this word order, in his famous article 'The knowledgecreating company' (Nonaka 1991). Neither did he or his colleague Takeuchi use the term in their best-selling book The Knowledge-creating Company: How Japanese Companies Create the Dynamics of Innovation (Nonaka and Takeuchi 1995), except when referring to publications about this idea (for example, Nonaka and Takeuchi 1995, p. 223) (they did, however, use the expression 'management of knowledge', Nonaka and Takeuchi 1995, p. viii). Therefore, Davenport and Prusak's (1998) Working Knowledge: How Organisations Manage What They Know, in 
which the term knowledge management is central, is perhaps a better representative, or 'bible', of the idea of knowledge management.

Lately, knowledge management has become increasingly popular, both among organizational actors and scholars, and, thus, a fashion (for example, Raub and Rüling 2001; Scarbrough et al. 2005; Perkmann and Spicer 2008). Just like any other fashionable management idea (Benders and Van Veen 2001), knowledge management is said to be vague and ambiguous (for example, Baines 1997; Gumbley 1998; Despres and Chauvel 1999; Stimpson 1999; Roberts 2000; Denton 2001; Scarbrough and Swan 2001; Wilson 2002; Beeslay and Cooper 2008). There are many examples in the literature where knowledge management is claimed to be something that is relevant to, more or less, all organizations (see, for example, Wiig 1997; Ichijo and Nonaka 2007). Others argue that those organizations that adopt knowledge management increase their performance (for example, Marqués and Simón 2006; Yadav and Singh 2013).

\section{RESEARCHERS' ROLE: BALANCING BETWEEN ADOPTION, ABANDONMENT AND ADAPTATION}

With the hype also comes the two-sided extremist positions that are taken (Driver 2002) in the literature. A large number of works blindly supports the idea while a much smaller group of authors one-sidedly criticizes it (Örtenblad 2011). In the case of knowledge management, most works are positive and knowledge management is assumed and described as being able to bring various kinds of advantages:

It is agreed that successful companies are those that create new knowledge, disseminate it widely throughout the organization and quickly embody it into new technologies and products. This process fuels innovation and develops lasting competitive advantage. Indeed, in a top-line finding of a survey of Ernst \& Young (1997), executives see innovation as the greatest payoff from KM, even though KM efforts have so far concentrated on achieving productivity gains. Henry and Walker (1991) link innovation to 'new knowledge' or new constructed knowledge by showing how tacit knowledge can become explicit knowledge. Other benefits include increased organizational learning, improved intellectual asset management, increased operational efficiency, time-to-market improvement, and continuous improvement (Demarest, 1997). (Metaxiotis et al. 2005, p.9)

By managing knowledge, organizations can:

- improve efficiency

- improve the market position by operating more intelligently on the market 
- enhance the continuity of the company

- enhance the profitability of the company

- optimize the interaction between product development and marketing

- improve the relevant (group) competencies

- make professionals learn more efficiently and more effectively

- provide a better foundation for making decisions like make-or-buy of new knowledge and technology, alliances and merges

- improve communication between knowledge-workers

- enhance synergy between knowledge-workers

- ensure that knowledge-workers stay with the company

- make the company focus on the core business and on critical company knowledge. (uit Beijerse 1999, p.97)

In one of the much fewer and very critical works, Wilson (2002) suggests that knowledge management is merely 'an umbrella term for a variety of organizational activities, none of which are concerned with the management of knowledge'. But to 'either idealize or marginalize managerial rationality', as is the tendency within studies of the adoption of management ideas (Sturdy 2004, p. 155), is not the focus of this book. This book has a more constructive yet reflective and critically examining orientation.

After having reached a certain maturity as a fashion, that is, after the worst hype is over and people do not have to use the term merely for the cause of not appearing illegitimate, then there is time for reflection and time to explore more reflectively what the management idea can contribute in an instrumental sense. Not only managers and other organizational actors are fashion followers, but academics are as well (Bort and Kieser 2011) and tend to surrender the management ideas after a while. As a matter of fact, the best time to explore what the 'fashion' actually has to offer and can contribute might be right after the first fashion wave has faded. The idea of knowledge management now seems to have reached such a state of maturity (McAdam and Reid 2001; Salojärvi et al. 2005). Thus, in agreement with authors such as Kieser (1997), Collins (2000) and Sorge and Van Witteloostuijn (2004, p. 1208), who argue that management fashions actually might add at least some value to the organizations in which they are used, this book's premise is that there are both pros and cons to knowledge management, and that various elements or parts of the idea of knowledge management might be more or less relevant to organizations in different contexts (at the least, this is an open question).

Knowledge management is regarded, by some scholars, to be in need of contextualization (Glisby and Holden 2003; Strach and Everett 2004; Franken and Braganza 2006; Liebowitz 2008). That is, there is a belief that there is no such thing as a single definition or model of knowledge management that can be fully relevant to organizations no matter of context. This is also an assumption in this book. Not necessarily does a certain 
general knowledge management model need to be adapted to fit and be of relevance to organizations in various contexts, but there is a need to question and, thus, examine the relevance of it. In some contexts the general model might work fine without first having to undergo changes, while it might need to be adapted to be successfully adoptable in other contexts. The literature does not give many insights on how to accomplish a contextualization of knowledge management. Accordingly, all those considering practising knowledge management can be said to, depending on where one comes from, either have a large degree of freedom (see, for example, Røvik 1996; Alvarez 1998; Scarbrough and Swan 2001) or be helplessly in need of assistance from consultants or researchers in adapting the idea (Scarbrough and Swan 2001, p. 8).

Researchers should contribute to the contextualization of knowledge management for, mainly, two reasons: researchers can be assumed to have more knowledge as well as being less biased than, for instance, organizational actors. Researchers hardly know more about the exact situation or need of the particular organization, and, thus, it might not be reasonable to request that researchers customize the knowledge management idea to each individual organization's needs. But they can be assumed to have more knowledge on what organizations within certain contexts generally need, and also on how to judge and advise on the relevance of knowledge management, according to a certain definition, to specific contexts. There is always a risk that organizational actors adopt a whole idea or elements of the idea that may help to put the organization in a favourable light but actually would be harmful for the organization to practise. Likewise, organizations may reject knowledge management or important elements of it, which for convenience reasons they may claim are not applicable, while it could be very beneficial to adopt these. Thus, researchers could help in certifying a sound balance between adoption, abandonment and adaptation of any management idea and in this case the particular idea of knowledge management. Researchers should assist in advising on the relevance and, potentially, the adaptation of decontextualized versions of knowledge management to organizations within specific contexts and, ultimately, in contributing to the construction of a contingency model of the relevance of the knowledge management idea to organizations in different contexts. In comparison with works in which a small group of scholars suggest how knowledge management should vary in accordance with certain factors and, thus, in many different situations (for example, Becerra-Fernandez and Sabherwal 2001; Wu and Ho 2005; Ang and Massingham 2007; McIver and Lengnick-Hall 2011; Chen et al. 2012), the present book involves many authors who each is an expert on knowledge management within a certain context. 
In fact, there are already quite a number of existing works in which the knowledge management idea is put into various contexts such as shopping centres (for example, Dennis et al. 2001), public administration (for example, Wiig 2002), health care (for example, Van Beveren 2003), Indian public and private sectors (for example, Chawla and Joshi 2010), small and medium-sized enterprises (SMEs) (for example, Coyte et al. 2012) and the United Arab Emirates (for example, Siddique 2012). However, the large majority of these works can generally be regarded as isolated contributions (as will be considered in more depth in Chapter 2) rather than as systematically contributing to a contingency model. The main problem is that many of them consider knowledge management to be an ideal whose relevance does not need to be critically examined. The time has come to more systematically outline in which situations which elements of the idea of knowledge management are relevant and preferable, and in which situations they are not. The vision is to move this emerging research field away from a situation where it is impossible to tell whether the incongruences between recommendations in different studies can be explained by the fact that the researchers have used different methods or research designs, applied different stakeholder perspectives, used different definitions of knowledge management, studied different industries or investigated industries located within different national cultures. This is, mainly, what this book is about.

The overall aims of this book are: (1) to pay attention to and acknowledge the study of the relevance of knowledge management to organizations in different contexts as an emerging research field; (2) to explore the universality of the idea of knowledge management; (3) to question the claim that there is one size of knowledge management that fits all; and (4) to evaluate and discuss the relevance of certain definitions of knowledge management. The book looks at previous studies (past), shows some relevant new works (present) and draws up lines for further research (future). A more utilitarian aim of the book is to offer knowledge (as well as support for further knowledge-seeking) on what organizations in various particular contexts need to do to implement and practise knowledge management or, if this is not recommendable, how the knowledge management idea needs to be adapted to become relevant to organizations within a particular context.

One can assume that at least those who are interested in adopting knowledge management and using it instrumentally for increased technical efficiency (Abrahamson 1991) are likely to take an interest in the rise

of a contingency model of knowledge management (see Örtenblad 2010). This reasoning is based on the presumption that management ideas' 'clear structure permits swift and precise action' (Fink 2003, p. 47). There 
may also be arguments against the adoption of knowledge management in certain situations. An open discussion on the relevance of knowledge management that is not limited to values such as effectiveness and profit maximization but also considers, for instance, increased well-being, societal effectiveness or welfare (Örtenblad 2011, 2013; Örtenblad and Koris 2014) may be even more helpful and would probably also appeal to and be helpful to a broader group of stakeholders, such as employees and society. A general overview definition of knowledge management is needed for these purposes, and is sketched out in Chapter 3.

\section{THE REMAINDER OF THIS BOOK}

\section{Part I Introduction and Background}

Part I of the book comprises an introduction and background. In addition to the current chapter, I present in Chapter 2, 'Previous research on knowledge management in various contexts', an analysis of the contributions from some previous studies on the relevance of the idea of knowledge management to organizations in particular contexts. To make it possible to compare between the chapters on the relevance of knowledge management to organizations in various contexts, an inclusive and normative definition model is needed. Thus, in Chapter 3, 'A normative model of knowledge management effectiveness' by Paul S. Myers outlines such a common starting point for the remainder of the book.

\section{Part II Knowledge Management in Context}

Part II of the book contains chapters on the relevance of the idea of knowledge management to certain contexts and on the universality of the idea. It consists of three subsections. Section A examines the relevance of knowledge management to various industries and sectors. In Chapter 4, 'Knowledge management in law firms', Cathrine Filstad and Petter Gottschalk connect knowledge management with law firms and in the following Chapter 5, 'Knowledge management in the police force', Filstad and Gottschalk connect it with the police force. Denise McDowall, Anita Rynne and Steven Talbot connect knowledge management with the army in Chapter 6, 'The Australian Army's knowledge management strategy: a reflexive organizational approach to knowledge capture and sharing' The relevance of knowledge management to elderly care organizations is discussed by Carina Abrahamson Löfström in Chapter 7, 'Knowledge management in elderly care'. David Coldwell and Andrea Fried deal with 
cross-cultural academic research in Chapter 8, 'Cross-cultural knowledge management in collaborative academic research'. Chapter 9, 'Knowledge management in energy sector organizations' by John S. Edwards looks at energy sector organizations. Eduardo Tomé and Gaby Neumann deal with organizations in the logistics industry in Chapter 10, 'Knowledge management in logistics industry organizations'. SMEs are discussed in Chapter 11, 'Knowledge management in small and medium-sized enterprises: navigating informality and resource constraints' by Thomas Garavan, Fergal O'Brien and Eamonn Murphy. The final chapter in this section, Chapter 12, 'Knowledge management, context and public policy: developing an analysis framework' by Deborah A. Blackman, Katie Moon, Stephen Harris and Stephen D. Sarre deals with the relevance of knowledge management to complex decision-making processes.

Section B focuses on religion and national culture. In Chapter 13, 'Islamic perspective of knowledge management', Aini Ahmad connects knowledge management with religion, and outlines what knowledge management would need to be like from an Islamic perspective. A second chapter on knowledge management and religion, Chapter 14, 'Buddhist perspective on knowledge management' by Otto Chang deals with the same issues as the previous chapter but connects instead to another of the world religions - Buddhism. Chapter 15, 'Knowledge management case studies in Mexico' by David Joaquín Delgado-Hernández is one of the few chapters in this book that connects knowledge management with a single national culture. Amit Mitra and Ximing Ruan take up the Chinese context in Chapter 16, 'Knowledge management in China's organizations'. In Chapter 17, 'Knowledge management and indigenous organizations with special reference to Tanzania and South Africa', Edda Tandi Lwoga, Christine Stilwell and Patrick Ngulube look at and compare knowledge management in two national cultures and draw some conclusions for indigenous organizations in general.

Table 1.1 provides an overview of the chapters in Part II, Sections A and $\mathrm{B}$, on knowledge management in context, the main questions dealt with in each chapter and the main source(s) for each chapter.

Section C is a special section on Nonaka's (and colleagues') knowledge management models - especially SECI - and the universality of these. On the basis of an empirical study, Jacky Hong, Robin Snell and Carry Mak discuss the universality of the SECI model to organizations in China in Chapter 18, 'Contextualizing Nonaka's theory of knowledge in China: when Samurai meets Bruce Lee'. Nigel Holden and Martin Glisby reason more generally on the universality of the SECI model in Chapter 19, 'The Nonaka-Takeuchi model of knowledge conversion: a discussion of many contexts of Japanese history and culture'. 


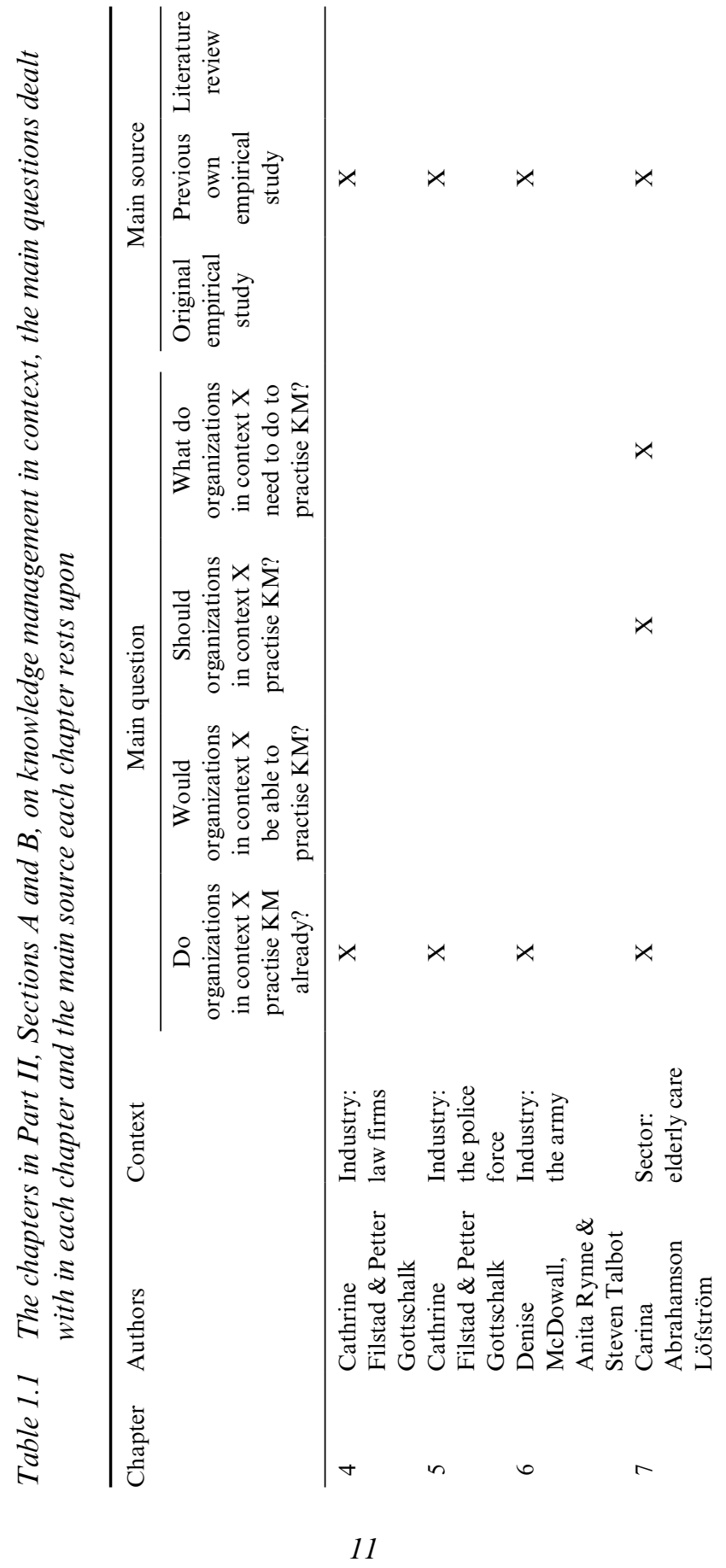




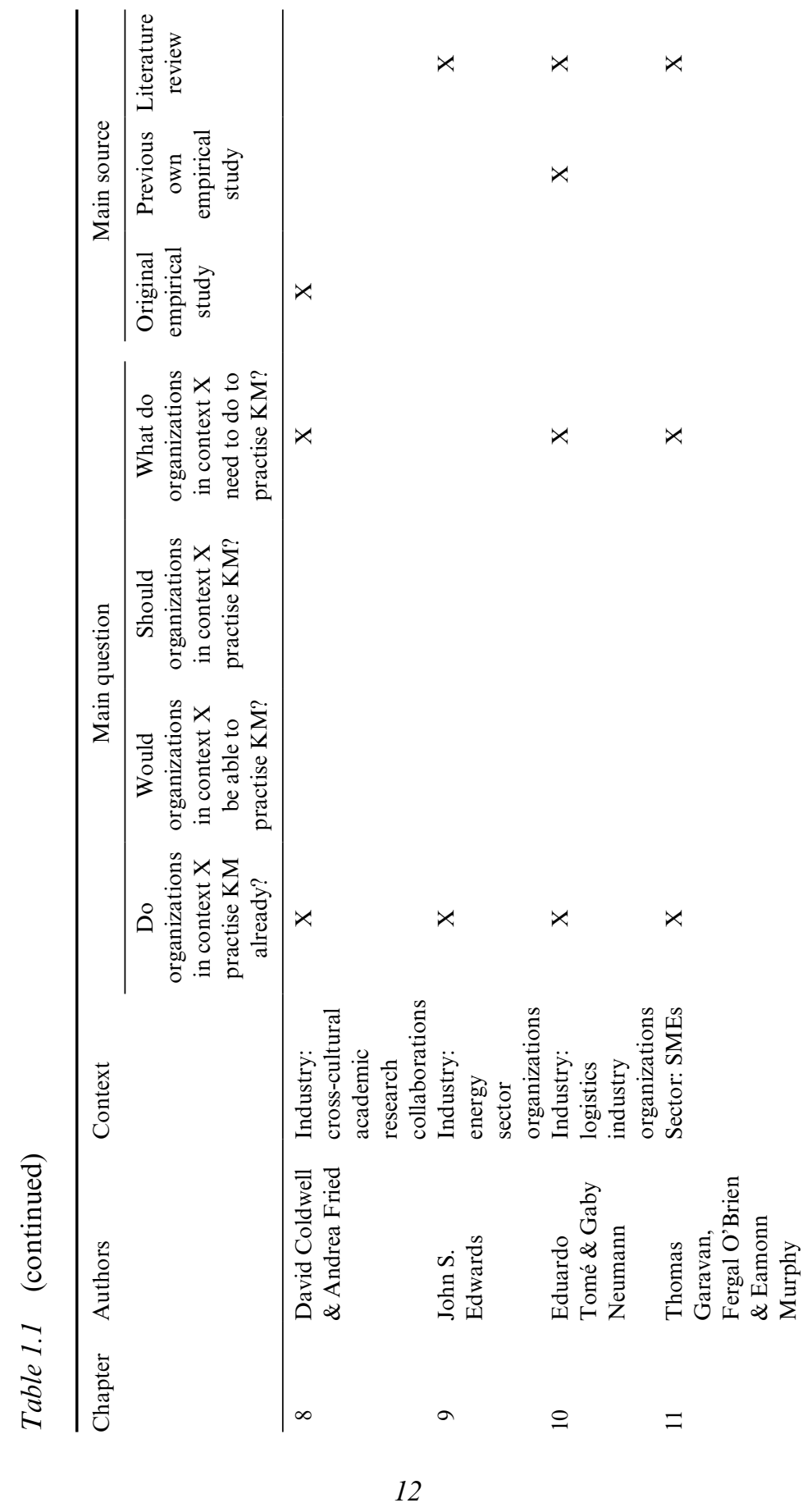




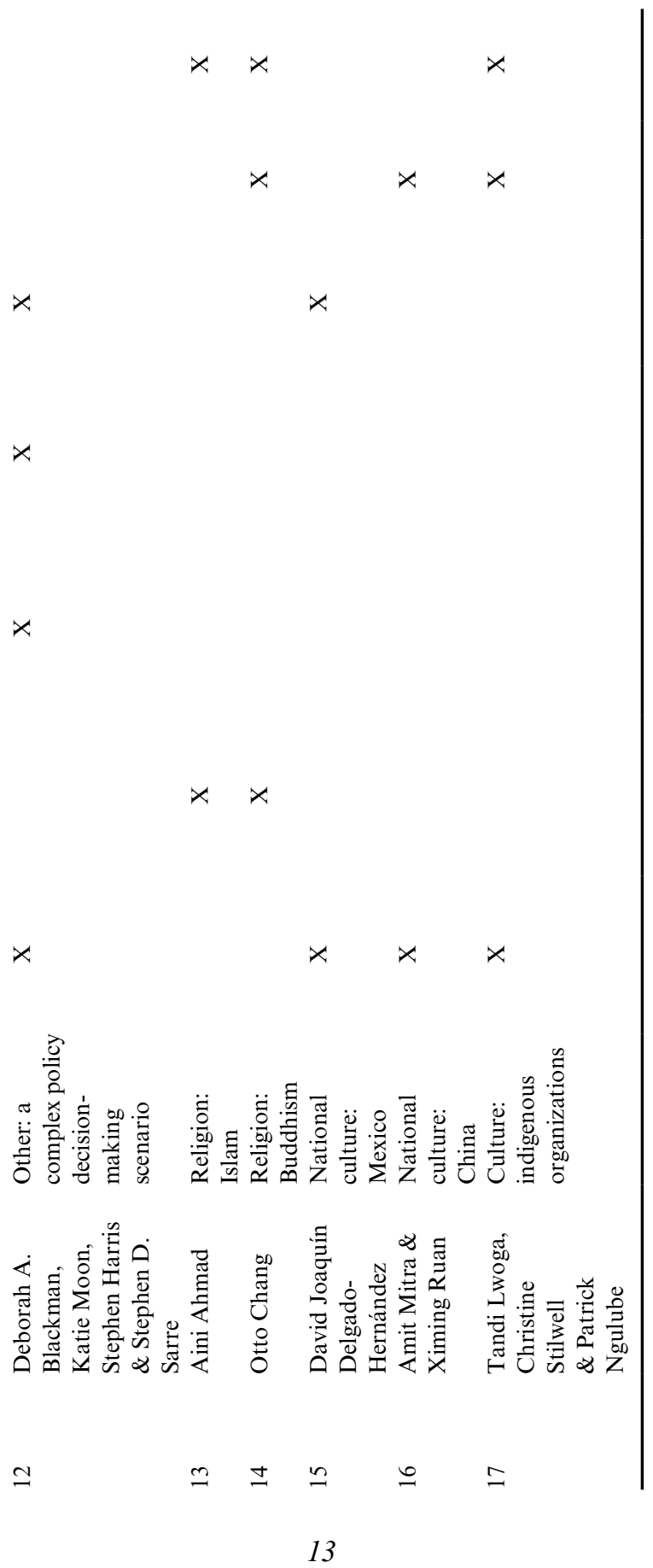




\section{Part III Reflections on Knowledge Management}

Part III of the book contains chapters in which the authors reflect on the concept of knowledge management or, as in the final chapter of the book, on the previous parts of the book (especially the chapters in Part II). First, three chapters reflect on the definition of knowledge management. Chapter 20, 'On the complexity of knowledge management given the tacitness of knowledge in organizations' by Thomas Garavan, Fergal O'Brien and Eamonn Murphy discusses some peculiarities connected to 'tacit knowledge' and evaluates Myers's seven C's model on the basis of this aspect of knowledge management. Elena P. Antonacopoulou suggests that the definition presented in Chapter 3 needs to be extended in her Chapter 21, 'Tensions and extensions in knowledge integration and disintegration: rethinking the man-agement of knowledge in organizations'. In Chapter 22, 'Alternative knowledge management', Shih-wei Hsu suggests two new definitions of knowledge management. Finally, in Chapter 23, 'Conclusions, a contingency model of knowledge management and recommendations for further research', I summarize the contributions of the book and outline some suggestions for further research within the area.

\section{REFERENCES}

Abrahamson, E. (1991), 'Managerial fads and fashions: the diffusion and rejection of innovations', Academy of Management Review, 16 (3), 586-612.

Alvarez, José L. (1998), 'The sociological tradition and the spread and institutionalization of knowledge for action', in José L. Alvarez (ed.), The Diffusion and Consumption of Business Knowledge, London: Macmillan, pp. 13-57.

Ang, Z. and P. Massingham (2007), 'National culture and the standardization versus adaptation of knowledge management', Journal of Knowledge Management, 11 (2), 5-21.

Baines, A. (1997), 'Exploiting organizational knowledge in the learning organization', Work Study, 46 (6), 202-6.

Beal, G.M. (1980), 'Knowledge generation, organization dissemination and utilization for rural development', Paper presented at the 5th World Congress for Rural Sociology, Mexico City, August.

Becerra-Fernandez, I. and R. Sabherwal (2001), 'Organizational knowledge management: a contingency perspective', Journal of Management Information Systems, 18 (1), $23-55$.

Beesley, L.G.A. and C. Cooper (2008), 'Defining knowledge management (KM) activities: towards consensus', Journal of Knowledge Management, 12 (3), 48-62.

Benders, J. and K. Van Veen (2001), 'What's in a fashion? Interpretative viability and management fashions', Organization, $8(1), 33-53$.

Bort, S. and A. Kieser (2011), 'Fashion in organization theory: an empirical analysis of the diffusion of theoretical concepts', Organization Studies, 32 (5), 655-81.

Caldwell, L.K. (1967), 'Managing the scientific super-culture: the task of educational preparation', Public Administration Review, 27 (2), 128-33.

Carroll, J.D. and N. Henry (1975), 'Introduction [to "a symposium, knowledge management"]', Public Administration Review, 35 (6), 567. 
Chawla, D. and H. Joshi (2010), 'Knowledge management initiatives in Indian public and private sector organizations', Journal of Knowledge Management, 14 (6), 811-27.

Chen, J., P.Y.T. Sun and R.J. McQueen (2010), 'The impact of national cultures on structured knowledge transfer', Journal of Knowledge Management, 14 (2), 228-42.

Chen, Y.-Y., S-P. Yeh and H-L. Huang (2012), 'Does knowledge management "fit" matter to business performance?', Journal of Knowledge Management, 16 (5), 671-87.

Collins, David (2000), Management Fads and Buzzwords: Critical-practical Perspectives, London: Routledge.

Coyte, R., F. Ricceri and J. Guthrie (2012), 'The management of knowledge resources in SMEs: an Australian case study', Journal of Knowledge Management, 16 (5), 789-807.

Czarniawska, Barbara and Guje Sevón (eds) (1996), Translating Organizational Change, Berlin: de Gruyter,

Czarniawska, Barbara and Guje Sevón (eds) (2005), Global Ideas: How Ideas, Objects and Practices Travel in the Global Economy, Malmö, Sweden: Liber.

Davenport, Thomas H. and Laurence Prusak (1998), Working Knowledge: How Organizations Manage What They Know, Boston, MA: Harvard Business School Press.

Dennis, C., D. Marsland and T. Cockett (2001), 'Data mining for shopping centres: customer knowledge-management framework', Journal of Knowledge Management, 5 (4), 368-74.

Denton, D.K. (2001), 'Better decisions with less information', Industrial Management, 43 (4), $21-5$.

Despres, C. and D. Chauvel (1999), 'Knowledge management(s)', Journal of Knowledge Management, 3 (2), 110-20.

Driver, M. (2002), 'The learning organization: Foucauldian gloom or utopian sunshine?', Human Relations, 55 (1), 33-53.

Fink, D. (2003), 'A life cycle approach to management fashion: an investigation of management concepts in the context of competitive strategy', Schmalenbach Business Review, 55 (1), 46-59.

Franken, A. and A. Braganza (2006), 'Organisational forms and knowledge management: one size fits all?', International Journal of Knowledge Management Studies, 1 (1-2), 18-37.

Gates, B.L. (1975), 'Knowledge management in the technological society: government by indicator', Public Administration Review, 35 (6), 589-93.

Glisby, M. and N. Holden (2003), 'Contextual constraints in knowledge management theory: the cultural embeddedness of Nonaka's knowledge-creating company', Knowledge and Process Management, 10 (1), 29-36.

Gumbley, H. (1998), 'Knowledge management', Work Study, 47 (5), 175-7.

Henry, N.L. (1974), 'Copyright: its adequacy in technological societies', Science, 186 (4168), 993-1004.

Ichijo, Kazuo and Ikujiro Nonaka (2007), 'Introduction: knowledge as competitive advantage in the age of increasing globalization', in Kazuo Ichijo and Ikujiro Nonaka (eds), Knowledge Creation and Management: New Challenges for Managers, Oxford: Oxford University Press, pp. 3-10.

Kieser, A. (1997), 'Rhetoric and myth in management fashion', Organization, 4 (1), 49-74.

Liebowitz, J. (2008), 'Think of others in knowledge management: making culture work for you', Knowledge Management Research and Practice, 6, 47-51.

Magnier-Watanabe, R. and D. Senoo (2010), 'Shaping knowledge management: organization and national culture', Journal of Knowledge Management, 14 (2), 214-27.

Marqués, D.P. and F.J.G. Simón (2006), 'The effect of knowledge management practices on firm performance', Journal of Knowledge Management, 10 (3), 143-56.

McAdam, R. and R. Reid (2001), 'SME and large organisation perceptions of knowledge management: comparisons and contrasts', Journal of Knowledge Management, 5 (3), $231-41$.

McIver, D. and C.A. Lengnick-Hall (2011), 'Knowledge management processes and unit performance: a contingency perspective', Academy of Management Proceedings, January (Meeting Abstract Supplement), 1-7.

Metaxiotis, K., K. Ergazakis and J. Psarras (2005), 'Exploring the world of knowledge 
management: agreements and disagreements in the academic/practitioner community', Journal of Knowledge Management, 9 (2), 6-18.

Meyer, J.W. and B. Rowan (1977), 'Institutionalized organizations: formal structure as myth and ceremony', American Journal of Sociology, 83 (2), 340-63.

Nonaka, I. (1991), 'The knowledge-creating company', Harvard Business Review, 69 (6), 96-104.

Nonaka, Ikujiro and Hirotaka Takeuchi (1995), The Knowledge-creating Company: How Japanese Companies Create the Dynamics of Innovation, Oxford: Oxford University Press.

Örtenblad, A. (2007), 'The evolution of popular management ideas: an exploration and extension of the old wine in new bottles metaphor', International Journal of Management Concepts and Philosophy, 2 (4), 365-88.

Örtenblad, A. (2010), 'Who needs contingency approaches and guidelines in order to adapt vague management ideas?', International Journal of Learning and Change, 4 (1), 64-76.

Örtenblad, Anders (2011), Making Sense of the Learning Organization: What is it and Who Needs it?, Kuala Lumpur: Yayasan Ilmuwan.

Örtenblad, Anders (2013), 'Who is the learning organization for? A stakeholder contingency approach to contextualizing managerial panaceas', in Anders Örtenblad (ed.), Handbook of Research on the Learning Organization: Adaptation and Context, Cheltenham, UK and Northampton, MA, USA: Edward Elgar, pp. 289-305.

Örtenblad, A. and R. Koris (2014), 'Is the learning organization idea relevant to higher educational institutions? A literature review and a "multi-stakeholder contingency approach", International Journal of Educational Management, 28 (2), 173-214.

Perkmann, M. and A. Spicer, A. (2008), 'How are management fashions institutionalized? The role of institutional work', Human Relations, 61 (6), 811-44.

Raub, S. and C-C. Rüling (2001), 'The knowledge management tussle: speech communities and rhetorical strategies in the development of knowledge management', Journal of Information Technology, 16 (2), 113-30.

Roberts, B. (2000), 'Pick employees' brains', HR Magazine, 45 (2), 115-20.

Røvik, Kjell A. (1996), 'Deinstitutionalization and the logic of fashion', in Barbara Czarniawska and Guje Sevón (eds), Translating Organizational Change, Berlin: de Gruyter, pp. 139-72.

Røvik, K.A. (1998), 'The translation of popular management ideas: towards a theory', Paper presented at the EGOS 14th Colloquium, Maastricht, the Netherlands, 9-11 July.

Røvik, K.A. (2011), 'From fashion to virus: an alternative theory of organizations' handling of management ideas', Organization Studies, 32 (5), 631-53.

Salojärvi, S., P. Furu and K.-E. Sveiby (2005), 'Knowledge management and growth in Finnish SMEs', Journal of Knowledge Management, 9 (2), 103-22.

Scarbrough, H., M. Robertson and J. Swan (2005), 'Professional media and management fashion: the case of knowledge management', Scandinavian Journal of Management, 21 (2), 197-208.

Scarbrough, H. and J. Swan (2001), 'Explaining the diffusion of knowledge management: the role of fashion', British Journal of Management, 12 (1), 3-12.

Siddique, C.M. (2012), 'Knowledge management initiatives in the United Arab Emirates: a baseline study', Journal of Knowledge Management, 16 (5), 702-23.

Sorge, A. and A. Van Witteloostuijn (2004), 'The (non)sense of organizational change: an essay about universal management hypes, sick consultancy metaphors, and healthy organization theories', Organization Studies, 25 (7), 1205-31.

Stimpson, J. (1999), 'In the know: getting in on the ground floor of knowledge management', Practical Accountant, 32 (6), $34-40$.

Šrach, P. and A. Everett (2004), 'Knowledge management is not universal: a contemplation of Japanese practices', in Proceedings of the 9th Asia-Pacific Decision Sciences Institute Conference, Seoul: Asia-Pacific Decision Sciences Institute, available at http://iceb.nccu. edu.tw/proceedings/APDSI/2004/pdf/114.pdf (accessed 2 February 2014). 
Sturdy, A. (2004), 'The adoption of management ideas and practices: theoretical perspectives and possibilities', Management Learning, 35 (2), 155-80.

uit Beijerse, R.P. (1999), 'Questions in knowledge management: defining and conceptualising a phenomenon', Journal of Knowledge Management, 3 (2), 94-109.

Van Beveren, J. (2003), 'Does health care for knowledge management?', Journal of Knowledge Management, 7 (1), 90-5.

Van Mesdag, M. (1983), 'Too much information, not enough knowledge', Chief Executive, London, May, 38-9.

Wiig, K.M. (1997), 'Knowledge management: an introduction and perspective', Journal of Knowledge Management, 1 (1), 6-14.

Wiig, K.M. (2002), 'Knowledge management in public administration', Journal of Knowledge Management, 6 (3), 224-39.

Wilson, T.D. (2002), 'The nonsense of "knowledge management", Information Research, 8 (1), available at http://informationr.net/ir/8-1/paper144.html (accessed 7 November 2004).

Wu, W.H. and C.F. Ho (2005), 'A contingency theoretic model of knowledge management: case studies for high technology and traditional industries', Proceedings of the Third Workshop on Knowledge Economy and Electronic Commerce, Taipei, Taiwan, June, available at http://moe.ecrc.nsysu.edu.tw/Chinese/workshopC/2005/SYS-07.pdf (accessed 5 February 2014).

Yadav, N. and S.P. Singh (2013), 'A role of knowledge management in organizational performance', International Journal of Scientific and Engineering Research, 4 (11), 195-201, available at http://www.ijser.org/researchpaper\%5CA-Role-of-Knowledge-Managementin-Organizational-Performance.pdf (accessed 25 January 2014). 